International Journal of Business and Management 2 (4): 29-35, 2018

e-ISSN: 2590-3721

(C) RMP Publications, 2018

DOI: $10.26666 /$ rmp.ijbm.2018.4.5

\title{
Promoting Entrepreneurial Competencies via Education: Is Malaysian Polytechnic Entrepreneurship Education Effective?
}

\author{
Asliza Yusoff and Salehan Marsim \\ Department of Commerce, Politeknik Sultan Azlan Shah, 35950 Behrang Stesen, Perak, Malaysia.
}

\begin{abstract}
Malaysian Polytechnic has been actively participating in providing entrepreneurship education (EE) and training to improve basic skills and encourage self-employment among its graduates. Sadly, a scrutiny of the available literature suggests that Malaysian polytechnic entrepreneurship education (MPEE) is ineffective as it fails to inculcate entrepreneurial spirit among the students. Students who have finished the MPEE were reported to have not embedded with enterprising knowledge, business skills and attributes during their study in polytechnics. However, these findings obviously demand further clarification. First, although entrepreneurship is indeed a very long process and cannot be created overnight, previous studies measured the effectiveness of MPEE by looking into students' readiness for entrepreneurship. Although scholars have argued that entrepreneurial readiness or intention is the proximal determinant of entrepreneurial behaviour, intention alone is not enough in measuring entrepreneurship as it does not lead to immediate action. Second, previous studies also missed to apply the regression method in their analysis to investigate the impact of MPEE on students' entrepreneurial development, leaving both theoretical and methodological gaps to be filled by the current study. Based on this justifications, this study proposes that the effectiveness of MPEE can be studied by looking at how it creates students' intellectual capital, which is the asset that are garnered from an investment in EE, and students' entrepreneurial behaviour via a longitudinal design. This effort is deemed important since understanding the effectiveness of MPEE will bring substantial value to the overall educational, economic, and societal well-being in the long run. The significance of this study lies in its effort to reveal the effectiveness of MPEE by investigating its impact on 'the other side' of entrepreneurial intention, which is its behavioural aspect.
\end{abstract}

Key words: Malaysian Polytechnic, Entrepreneurship education, Intellectual capital, Entrepreneurial behavior, Entrepreneurial competencies

\section{INTRODUCTION}

Entrepreneurship has been acknowledged to be a powerful mechanism in providing employment opportunity which may lead to a falloff in unemployment [1], [2], [3]. There are strands of empirical research that have showed that the engines for entrepreneurship development are based on training and inculcating entrepreneurship work culture during their study at the tertiary level [4], [5], [6]. Based on the assumption that 'entrepreneurs can be made' [7], the importance of entrepreneurship education (EE) in the development of future entrepreneurs has become a major concern of many parties including the policy makers. In Malaysia, EE is seen as crucial for the success of the nation's new mission of building a high- income economy [8]. Thus, the Malaysian government had put the utmost efforts toward the realization of the New Economy Model (NEM), through the launch of the development of the Higher Education Institute Entrepreneurship Foundation (HEIEF) on February 18, 2010. The main mission of the HEIEF is to create highquality human assets with the intellectual attributes and entrepreneurship values required to achieve the NEM by 2020. As one of the Malaysian higher education providers that has been standing high in the education market, Malaysian Polytechnic has been actively participating in providing entrepreneurship education and training to improve basic skills and encourage selfemployment among its students and graduates [9].

However, there is a great concern of the researchers regarding the issue of the effectiveness of the EE 
provided by the Malaysian polytechnics. As reported by author [10] Malaysian polytechnic entrepreneurship education (MPEE) was found to be ineffective as it fails to inculcate entrepreneurial spirit among the students that they were not embedded with enterprising knowledge, business skills and attributes during their study in polytechnics. The study by author [10] had motivated another study to continue investigating the effectiveness of the MPEE. The recent study by author [8], however, tend to focus on the impact of entrepreneurial teaching dimension as perceived by the students as well as students' readiness for entrepreneurship. However, the loophole in the MPEE remains. As reported by author [9], only 18.7 percent of polytechnic graduates had embarked in selfemployment while others chose to work at existing public and private organizations.

Furthermore, an entrepreneurship is indeed a very long process. Thus, it cannot be created overnight. Although scholars has argued that intention is the proximal determinant of entrepreneurial behaviour, intention alone is not enough in measuring entrepreneurship as it does not lead to immediate action [11], [12]. Both of the previous studies on MPEE however, did not investigate the effectiveness of MPEE in terms of how it impacts the students' intellectual capital, which is very crucial for venture creation. The availability of this intellectual capital, together with sufficient time given could result in a birth of an entrepreneurship venture.

Given the current unfavourable scenario of MPEE coupled with limited studies on MPEE in the literature, the current study proposes to investigate the impact of MPEE on students' intellectual capital and entrepreneurial behaviour via a longitudinal design. In addition, as financing is recognized as the most important regulator of the allocation of efforts in entrepreneurial initiatives [13], the ease of access to sources of financing should be considered as a structural factor that influence venture creation. Therefore, by employing a longitudinal approach, this study heeds the call by introducing and examining the role of an access to financial capital in strengthening the intentionbehaviour relationship. Proposed research framework is illustrated below.

\section{LITERATURE REVIEW}

Malaysian Polytechnic Entrepreneurship Education (MPEE)

There is evidence that academically educated entrepreneurs are more important in developing regional economies than entrepreneurs with a lower level of education [14], [15]. Traditional education is associated with only a transformation of knowledge and abilities, whereas entrepreneurship education, in contrast, is held up as a model for changing attitudes and motives [16], [17]. As a second pillar of the country's higher education provider [10], Malaysian polytechnic has been striving to produce talented and skilful entrepreneurs among its graduates. Despite of its 28 years in operation, the effectiveness of MPEE remains an issue that deserves attention from scholars as well as policy makers.

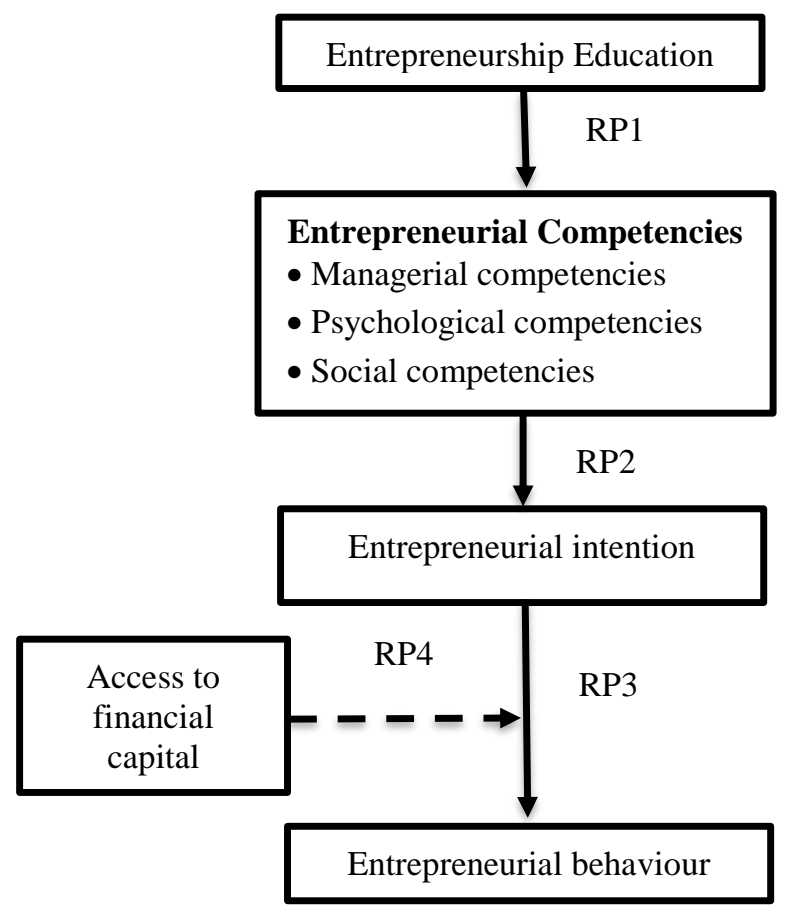

Figure 1: Proposed research framework

MPEE was developed to offer students a chance to see the latest developments, thus allowing them a clearer view on how to implement these developments in a future venture creation and in management. In response to the growing demand of entrepreneurship education, Malaysian polytechnics have created a variety of course offerings. These range from the traditionally structured courses, consisting of lectures, venture design projects, case studies, and readings, to the innovative courses developed to address the unique personality characteristics of the entrepreneurship students. Based on the work of author [18], MPEE has classified the types EE offered into three categories, which seem to be related to the individual's stage of development: business awareness education and infield education and training for small business ownership (generalized entrepreneurial education); specialist education which is conceived to enable people to update their skills 
(augmented) and education to build self-determination to start their own enterprises (motivational).

In Malaysian polytechnics, generalized EE aims to give students an academically meticulous learning that can be interpreted into a real-world value [17]. To achieve this objective Malaysian polytechnics offer courses such as DPB2012 - Entrepreneurship, DPB 5063 - Digital Entrepreneurship, DPB 3013 - Principle of Management. On the other hand, motivational EE aims to motivate students to choose entrepreneurship as their career choice. According to author [19] people are more likely to follow the attitude and behaviour of those they approve of. At Malaysian polytechnics, motivational EE is implemented by involving students in entrepreneurial related activities such as seminar, motivational talk by real world successful entrepreneurs, engagement in entrepreneurship day, participation in a hands-on experience in producing products for entrepreneurship activities and etc. By offering this kind of platforms, students are exposed to and have opportunities to interact with entrepreneurs or their role models. The final category of EE offered by Malaysian polytechnics is augmented EE by which students are provided with opportunities for conducting feasibility studies, participating in case competition, participating in simulated or real business, and developing business plan. Augment EE of Malaysian polytechnics aims to develop self-efficacy among students, which is another important requirement for entrepreneurship [20].

\section{The impact of entrepreneurship education}

EE has been acknowledged to have a significant role in promoting entrepreneurial intentions and assisting further development of enterprising citizens [6]. EE is believed to contribute to the development of entrepreneurship by creating a large business opportunities and equipping students with innovative business skills [4]. Therefore students who are supplied with EE and enrolled in entrepreneurship courses are expected to be confident, motivated, proactive, innovative, willing to face entrepreneurship challenges, as well as have the substantial skills to work in a team. Overall, an effective EE is expected to develop knowledge, skill and competencies among the students [21].

According to the literature, the effectiveness of an EE clarifies the importance not only of the skills and knowledge necessary for entrepreneurial success, but also the psychological traits or competencies that are appropriate for that purpose [21]. Nonetheless, despite the supposed importance of entrepreneurial competencies, the literature on this aspect is still in its initial stages [22], partly because the term competency has been defined from different approaches and as a consequence has different meanings. Most of the previous studies on the impact of EE had focused how EE impact psychological competencies such as risktaking, proactiveness, self-efficacy, innovativeness, need for achievement, need for autonomy, and endurance [23], [21], [6]. In addition to psychological competencies, management and social competencies are also vital for entrepreneurship endeavour. Entrepreneurs also need to possess the hard skills that enable them to manage a business -the management competencies. Across the entrepreneurial process, individuals must have the specific skills they need to manage a venture. The management competencies are defined by the basic and specific competencies in business management (for example, author [24], and mostly they refer to the individual's ability to manage the entrepreneur himself/herself, business strategy, business resources, and human resources. Furthermore, since an entrepreneur acts within a social context and therefore has to interact with different players, another dimension of an entrepreneur's characteristics that would denote an individual's ability to interact effectively with others involves social competence. An entrepreneur's effectiveness in interacting with others, that is, his or her social competence, may also affect their entrepreneurial creation and success [25]. This assumption was based on predicting that the higher an entrepreneur's social competence, the greater the success one will attain along his or her entrepreneurial process. Hence the following research propositions are formulated:

Research proposition 1: Students' involvement in entrepreneurship education is positively related with the development of entrepreneurial competencies (i.e. managerial, psychological and social competencies).

\section{Entrepreneurial competencies and intention}

According to the human capital theory, the development of entrepreneurship can be influenced by entrepreneur's characteristics which can be organized into key competency domains [26]. Entrepreneurial competencies have implications for motivation and action [21] which later could enhance entrepeneurial 
intention. In this case, individuals who possess greater levels of competencies will achieve greater performance outcomes including the creation of entrepreneurial intention and actual entrepreneurship behaviour. Literature has emphasized that individual entrepreneurial competence is very crucial in the early stage of starting a business [27] because competent individuals are innately able in a variety of tasks [28]. This valuable ability would later enhance their confidence that the performance of a specific behaviour will succeed.

Literature has also identified that individuals who are multi-skilled in a few areas (also known as balanced skill-mix), are more likely to opt in self-employment as a career choice [29]. Several emprical studies have confirmed the significant impact of entrepreneurial competencies on intention formation. For example, author [21] investigated how entrepreneurial competencies impact students intention for entrepreneurship and found entrepreneurial competencies in terms of self-efficacy, risk taking and innovativeness significantly influence intention formation among secondary school students. Similarly, author [30] studied entrepreneurial competencies in terms of ability to take risk among student found that entrepreneurial intention among students who perceived themselves as as risk averse, and students who perceived themselves as 'risk-loving' has differed significantly where students who are 'risk-loving' showed higher intention to venture in entrepreneurship for their living. Based on this, the current study proposes:

Research proposition 2: Students' entrepreneurial competencies (i.e. managerial, psychological and social competencies) are positively related with entrepreneurial intention.

\section{Entrepreneurial intention and behaviour}

Venture creation process includes sets of functions, activities, and actions that are concerned with pursuing opportunities and creation of enterprises [31], [32]. Thus, the set of actions in entrepreneurship behaviour such as productive process implementation, firm presence establishment, enterprise and financial structure creation, can actually be categorized as entrepreneurship behaviours. Accordingly, author [33] categorized entrepreneurship behaviour into five major categories, namely, gathering marketing information, estimating potential profit, finishing the groundwork for product or services, developing the company structure, and setting up business operations. Hence, this study conceptualizes entrepreneurial behaviour as a 'taking steps' ladder [32] to establish a firm which consists of these five important steps. Previous research has shown that some entrepreneurial behaviours are more likely to result in a successful start-up than are others [33].

The link between intentions and behaviour was empirically proven in author [34]'s study where a high correlation was found between these two constructs that students who have shown high intention for entrepreneurship have also tended to be engaged in at least two entrepreneurial activities. This notion was also supported in author [35] whereby the authors provided evidence of the significant and positive impact of entrepreneurial intention on entrepreneurship behaviour 18 months after. Similarly, author [36] conducted a study among working age population in Western Finland reported that entrepreneurial intention were empirically proven to have subsequent effect on entrepreneurship behaviour three years after. A more recent study among adult population in Austria and Finland by author [37] found that intention was significantly translated into subsequent entrepreneurship behaviour within one year. Based on the above findings and on the fact that intention can shape subsequent behaviour [38], this study believes that students who have strong intention to perform an entrepreneurship activity will, at some point after their graduation, create or found a new entrepreneurship enterprise. Therefore, it is proposed that:

\section{Research proposition 3: Entrepreneurial intention is} positively related with entrepreneurial behaviour.

Individuals who have high intention for entrepreneurship are more likely to engage in right entrepreneurial activities in order to ensure the successfulness of the entrepreneurship business creation. Empirically, intention explains only a small variance in entrepreneurship behaviour [39], [40], [41], which is 28 percent on average [42]. Hence, there is a strong argument against relying on intention as a proxy to entrepreneurship behaviour. The link from intention to behaviour is still ambiguous and may depend on several exogenous factors that influence the intentionbehaviour relationship [43]. The existence of several 
impediments along the intention-behaviour path was also suggested by author [11].

One of the possible variable that could change the intensity of intention-behaviour relationship is an access to financial capital because it is one of the most critical factors affecting the entrepreneurial process [44]. According to author [13], financing is recognized as the most important regulator of the allocation of efforts in entrepreneurial initiatives. Meanwhile, author [45] noted that the sophistication of credit systems encourages financing for entrepreneurial projects. Financing difficulties encountered by entrepreneurs are therefore regularly cited as a barrier to the creation of new businesses [46], [47], [48], [49] as the lack of initial capital, the high cost of private financing, and the obvious difficulty with finding external resources, generally forces entrepreneurs to resort to public funding, through grants and/or low interest loans. In short, the ease of access to sources of financing should be considered as a structural factor that influence venture creation. Therefore, by employing a longitudinal approach, this study heeds the call by introducing and examining the role of an access to financial capital in strengthening the intentionbehaviour relationship. Hence, the following research proposition is formulated:

Research proposition 4: An access to financial resources strengthens the relationship between entrepreneurial intention and behaviour.

\section{CONCLUSION}

In equipping young entrepreneurs with the competencies needed for the twenty-first century successful entrepreneurs, entrepreneurship education is a means of preparing the entrepreneurs to be responsible and to be able to solve more complex, interlinked and fast-changing entrepreneurial problems. Hence, the entrepreneurship education provided by an educational institutional needs to be assessed in terms of its effectiveness by investigating how well it impacts students' entrepreneurial competencies. Effective MPEE should be able to develop the possession of managerial, psychological and social competencies its students. These competencies are the drivers that lead to a success of business activities by such a way that it helps future entrepreneurs to deal with negative and unfavourable business environments during the initial stage of business creation as well as for business growth and survival.

In studying entrepreneurship among youth, scholars should also look into 'the other side' of entrepreneurship which is the actual entrepreneurial behaviour instead of only investigating intention formation. This is because entrepreneurship is about wealth creation and intention alone could not provide that benefit to the entrepreneurs. Therefore, researches that seek to explore entrepreneurship should be conducted based on longitudinal design to understand entrepreneurship creation better.

\section{ACKNOWLEDGMENTS}

The author acknowledges the financial support from Ministry of Education Malaysia (Higher Education) and Politeknik Sultan Azlan Shah, Perak, Malaysia.

\section{REFERENCES}

[1] Buttar, H. M. 2015. Formation of entrepreneurial career intentions: the role of sociocognitive factors. J. Employ. Couns., 52, 2-17.

[2] Rideout, E. C. and Gray, D. O. 2013. Does entrepreneurship education really work? A review and methodological critique of the empirical literature on the effects of university-based entrepreneurship education. J. Small Bus. Manag., 51, 329-351.

[3] Virick, M., Basu, A. and Rogers, A. 2015. Antecedents of entrepreneurial intention among laid-off individuals: A cognitive appraisal approach. J. Small Bus. Manag., 53, 450-468,.

[4] Mohamed, Z., Rezai, G., Shamsudin, M. N. and Mahmud, M. M. 2012. Enhancing young graduates' intention towards entrepreneurship development in Malaysia. Educ. + Train., 54, 605618.

[5] Mohammad Nor, N. A. A., Nik Mohd Masdek, N. R. and Maidin, M. K. H. 2015. Youth inclination towards agricultural entrepreneurship. Econ. Technol. Manag. Rev., 10a, 47-55.

[6] Yusoff, A., Ahmad, N. H. and Abdul Halim, H. 2016. Entrepreneurial orientation and agropreneurial intention among Malaysian agricultural students: the impact of agropreneurship education. Adv. Business-Related Sci. Res. J., 7, 77-92.

[7] Henry, C., Hill, F. and Leitch, C. 2005. Entrepreneurship education and training: can entrepreneurship be taught? Part I. Educ. + Train., $47,98-111$.

[8] Othman, N. and Nasrudin, N. 2016. Entrepreneurship education programs in 
Malaysian polytechnics. Educ. + Train., 58, 882898.

[9] Ministry of Higher Education, 2017. Higher education statistics 2017. [Online]. Available: https://www.mohe.gov.my/muatturun/awam/statistik/2017-3/475-statistikpendidikan-tinggi-2017-bab-7-kajian-pengesanangraduan. [Accessed: 08-May-2018].

[10] Ismail, M. Z. and Ahmad, S. Z. 2013. Entrepreneurship education: An insight from Malaysian polytechnics. J. Chinese Entrep., 5, 144-160.

[11] Carsrud, A. and Brännback, B. 2011 Entrepreneurial motivations: What do we still need to know? J. Small Bus. Manag., 49, 9-26.

[12] Saeed, S., Muffatto, M. and Yousafzai, S. Y. 2014. Exploring intergenerational influence on entrepreneurial intention: the mediating role of perceived desirability and perceived feasibility. Int. J. Entrep. Innov. Manag., 18, 134-153.

[13] Levie, J. and Autio, . 2008. A theoretical grounding and test of GEM model. Small Bus. Econ., 31, 235-263.

[14] Taatila, V. P. 2010. Learning entrepreneurship in higher education. Educ. +Training, 52, 48-61.

[15] Kwiek, M. 2012. Universities, regional development and economic competitiveness: the polish case, in R. Pinheiro, P. Benneworth, and G. A. Jones, (Eds), Universities and Regional Development: A Critical Assessment of Tensions and Contradictions, New York, NY: Routledge, 69-85.

[16] Hansemark, O. C. 1998. The effects of an entrepreneurship programme on need for achievement and locus of control of reinforcement. Int. J. Entrep. Behav. Res., 4, 28-50.

[17] Fayolle, A. and Gailly, G. 2015. The impact of entrepreneurship education on entrepreneurial attitudes and intention: hysteresis and persistence. J. Small Bus. Manag., 53, 75-93.

[18] Garavan, T. N. and O'Cinneide, B. 1994. Entrepreneurship education and training programmes: a review and evaluation-part 1. J. Eur. Ind. Train., 18, 3-12.

[19] Hasan, S. M., Ahmed Khan, E. and Nabi, M. N. U. Entrepreneurial education at university level and entrepreneurship development. Educ. + Train., 59, 888-906.

[20] Wilson, K. E., Vyakarnam, S., Volkmann, C., Mariotti, S. and Rabuzzi, D. 2009. Educating the next wave of entrepreneurs-unlocking entrepreneurial capabilities to meet the global challenges of the 21st century: a report of the global education initiative. World Economic Forum. Geneva.

[21] Sánchez, J. C. 2013. The impact of an entrepreneurship education program on entrepreneurial competencies and intention. J. Small Bus. Manag., 51, 447-465.

[22] Brinckmann, J. 2008. Competence of Top Management Teams and the Success of New Technology Based Firms. A Theoretical and Empirical Analysis Concerning Competencies of Entrepreneurial Teams and the Development of Their Ventures. Wiesbaden: Gabler Publish.

[23] Oosterbeek, H., van Praag, M. and Ysselstein, A. 2010. The impact of entrepreneurship education on entrepreneurship skills and motivation. Eur. Econ. Rev., 54, 442-454.

[24] Baum, J. R., Locke, E. A. and Smith, K. G. 2001. A multidimensional model of venture growth." Acad. Manag. J., 44, 292-303.

[25] Baron, R. and Markman, G. D. 2000. Beyond social capital: the role of social skills in entrepreneurs' success. Acad. Manag. Exec., 14, 106-116.

[26] Man, T. and Chan, T. 2002. The competitiveness of small and medium enterprises: A conceptualization with focus on entrepreneurial competencies. J. Bus. Ventur., 17, 123-142.

[27] Garzón, M. D. 2010. A comparison of personal entrepreneurial competences between entrepreneurs and CEOs in service sector. Serv. Bus., 4, 289-303.

[28] Åstebro, T. and Thompson, P. 2011. Entrepreneurs, jacks of all trades or Hobos? Res. Policy, 40, 637-649.

[29] Silva, O. 2007. The jack-of-all-trades entrepreneur: Innate talent or acquired skill? Econ. Lett., 97, 118-123.

[30] Zakaria, H., Adam, H. and Abujaja, A. M. 2014. Assessment of agricultural students of university for development studies intention to take up self employment in agribusiness. Int. J. Inf. Technol. Bus. Manag., 21, 53-67.

[31] Bygrave, W. D. and Hofer, C. W. 1991. Theorizing about entrepreneurship. Entrep. Theory Pract., 16, $13-22$.

[32] van der Zwan, P., Thurik, R. and Grilo, I. 2010 The entrepreneurial ladder and its determinants. Appl. Econ., 42, 2183-2191.

[33] Gatewood, E. J., Shaver, K. G. and Gartner, W. B. 1995. A longitudinal study of cognitive factors influencing start-up behaviors and success at venture creation. J. Bus. Ventur., 10, 371-391.

[34] Sequeira, J., Mueller, S. L. and Mcgee, J. E. 2007. The influence of social ties and self-efficacy in forming entrepreneurial intentions and motivating nascent behavior. J. Dev. Entrep., 12, 275-293.

[35] Rauch, A., Wiklund, J., Lumpkin, G. T. and Frese, M. 2009. Entrepreneurial orientation and business performance: An assessment of past research and suggestions for the future. Entrep. Theory Pract., 33, 761-787. 
[36] Kautonen, T., Van Gelderen, M. and Tornikoski, E. T. 2013. Predicting entrepreneurial behaviour: a test of the theory of planned behavior. Appl. Econ., 45, 697-707.

[37] Kautonen, T., Gelderen, M. and Fink, M. 2015. Robustness of the theory of planned behavior in predicting entrepreneurial intentions and actions. Entrep. Theory Pract., 39, 655-674.

[38] Ajzen, I. 2001. Nature and operation of attitudes. Annu. Rev. Psychol., 52, 27-58.

[39] Liao, Y. W., Wang, Y. S., Yeh, C. H. and Jansen, J. 2014. Exploring the relationship between intentional and behavioral loyalty in the context of e-tailing. Internet Res., 24, 668-686.

[40] MacGillivray, G. S. and Lynd-Stevenson, R. M. 2013. The revised theory of planned behavior and volunteer behavior in Australia. Community Dev., vol. 44, 23-37.

[41] Taylor, S. A. 2012. Evaluating digital piracy intentions on behaviors. J. Serv. Mark., 26, 427483.

[42] Sheeran, P. and Abraham, C. 2003. Mediator of moderators: Temporal stability of intention and the intention-behavior relation. Personal. Soc. Psychol. Bull., 29, 205-215.
[43] Krueger, N. F., Reilly, M. D. and Carsrud, A. L. 2000. Competing models of entrepreneurial intentions. J. Bus. Ventur., 15, 411-432.

[44] Vidal-Suñé, A. and López-Panisello, M. B. 2013. Institutional and economic determinants of the perception of opportunities and entrepreneurial intention. Investig. Reg., 26, 75-96.

[45] Leibenstein, H. 1968. Entrepreneurship and development. Am. Econ. Rev., 58, 72-83.

[46] Volery, T., Doss, T., Mazzarol, T. and Thein, V. 1997. Triggers and barriers affecting entrepreneurial intentionality: the case of Western Australian nascent entrepreneurs. Presented at 42nd ICSB World Conference, Geneva.

[47] Kouriloff, M. 2000. Exploring perceptions of a priori barriers to entrepreneurship: a multidisciplinary approach. Entrep. Theory Pract., 25, 59-79.

[48] Robertson, A., Collins, A., Medeira, N. and Slater, J. 2003. Barriers to start-up and their effect on aspirant entrepreneur. Educ. Train., 45, 308-316.

[49] Choo, S. and Wong, M. 2006. Entrepreneurial intention: triggers and barriers to new venture creations in Singapore. Singapore Manag. Rev., $28,47-64$. 